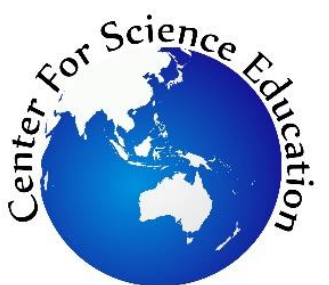

Tersedia online di EDUSAINS

Website: http://journal.uinjkt.ac.id/index.php/edusains

EDUSAINS,11(1), 2019, 99--104

Research Artikel

\title{
MODEL KELAS MULTIDIMENSIONAL: INOVASI PEMBELAJARAN ABAD 21 UNTUK MENINGKATKAN HASIL BELAJAR SISWA PELAJARAN ILMU PENGETAHUAN ALAM
}

\section{MULTIDIMENSIONAL CLASS MODELS: INNOVATION LESSONS IN THE 21ST CENTURY TO IMPROVE SCIENCE LEARNING OUTCOMES}

\author{
Fairus Qamila ${ }^{1}$, Dede Rosyada ${ }^{2}$ \\ ${ }^{1}$ Madrasah Tsanawiyah Pembangunan UIN Syarif Hidayatullah Jakarta,Indonesia \\ ${ }^{2}$ UIN Syarif Hidayatullah Jakarta, Indonesia \\ fairus.qamila@gmail.com
}

\begin{abstract}
The $21^{\text {st }}$ century learning is an effort to facilitate students in the $21^{\text {st }}$ century to get the best learning experience so they can achieve learning goals effectively. This research is aimed to recognize the enhancement of science student learning achivement with implementation of multidimensional classroom model. This research used a classroom action research from Kemmis and MC Taggart. The sample of 28 students. The research was done in three cycle. The percentage achivement every cycle was increased. By looking at the result obtained in each cycle, it can be concluded that there was enhancement of science student learning achivement with implementation of multidimensional classroom model.
\end{abstract}

Keywords: classroom action research; implementation; multidimensional classroom model; science; the 21 st century learning

\begin{abstract}
Abstrak
Pembelajaran abad 21 merupakan upaya memfasilitasi peserta didik di abad 21 untuk mengalami pengalaman belajar terbaik sehingga dapat mencapai tujuan pembelajaran secara efektif. Penelitian ini bertujuan untuk meningkatkan hasil belajar siswa pada pelajaran IPA dengan menerapkan model kelas multidimensional. Penelitian ini merupakan jenis Penelitian Tindakan Kelas (PTK) model Kemmis dan MC. Taggart. Sampel penelitian berjumlah 28 siswa. Penelitian ini dilakukan sebanyak 3 siklus. Persentase ketuntasan pada setiap siklus terus meningkat. Hasil penelitian menunjukan terdapat peningkatan hasil belajar siswa pada pelajaran IPA dengan menerapkan Model kelas Multidimensional.
\end{abstract}

Kata Kunci: implementas; IPA; model kelas multidimensional; pendidikan abad 21; penelitian tindakan kelas

Permalink/DOI: http://doi.org/10.15408/es.v11i1.11654 


\section{PENDAHULUAN}

Pada abad ke 21 persaingan terjadi dalam berbagai bidang kehidupan, diantaranya dibidang pendidikan. Pada abad ini, peserta didik dituntut untuk memiliki keterampilan hidup dan kemampuan yang sesuai dengan lapangan kerja. Peserta didik yang hidup pada abad 21 harus menguasai keilmuan, berketerampilan metakognitif, mampu berpikir kritis dan kreatif, serta dapat berkomunikasi atau berkolaborasi secara efektif (Greenstein, 2012: 41). US-based Partnership for $21^{\text {st }}$ Century Skills (P21), mengidentifikasi keterampilan abad 21 sebagai keterampilan 4C. Keterampilan 4C meliputi Critical thinking, Communication, Collaboration and Creativity.

Pembelajaran abad 21 merupakan upaya memfasilitasi peserta didik di abad 21 untuk mengalami pengalaman belajar terbaik sehingga dapat mencapai tujuan pembelajaran secara efektif. Dalam mencapai kondisi belajar yang ideal, kualitas pengajaran selalu terkait dengan penggunaan model pembelajaran yang optimal, ini berarti untuk mencapai kualitas belajar mengajar yang baik setiap mata pelajaran harus diorganisasikan dengan model pengorganisasian yang tepat dan selanjutnya disampaikan kepada siswa dengan model yang tepat pula (Sugiarti, 2018: 440).

Salah satu model kelas yang sesuai dengan keterampilan abad 21 adalah model kelas multidimensional. Model kelas ini merupakan suatu pendekatan yang menggunakan beberapa pendekatan terpadu yang mengacu pada pembelajaran kontekstual dengan mengutamakan keterlibatan siswa secara aktif di dalam pembelajaran. Model kelas ini bukan merupakan suatu model pembelajaran yang memiliki sistematika tertentu, melainkan model kelas yang menggunakan berbagai pendekatan yang digunakan dalam satu pembelajaran. Pendekatan secara kombinasi ini akan lebih baik daripada menggunakan salah satu pendekatan saja (Abdelhamid, 2008).

Model kelas multidimensional dirancang dengan melakukan pengelompokkan berdasarkan indeks kemampuan belajar siswa dalam mata pelajaran dan topik yang sama. Melalui hasil posttest pada pembelajaran sebelumnya, input siswa dapat ditentukan oleh hasil belajarnya. Jika kelompok siswa yang hasil posttest-nya dibawah Kriteria Belajar Minimal (KBM), maka siswa tersebut berhak memperoleh pengulangan. Sementara siswa yang sudah tuntas berhak memperoleh pokok bahasan baru. Hal ini disebabkan karena daya serap serta kemampuan siswa dalam menerima informasi berbeda-beda. Siswa dengan tingkat kemampuan yang tinggi memiliki permintaan perlakuan belajar yang berbeda dari lainnya. Demikian pula, siswa dengan tingkat kemampuan rendah menuntut perlakuan berbeda, karena mereka mempunyai hak yang sama untuk memperoleh kompetensi sesuai dengan tujuan kurikulum yang berlaku (Kauchak, 1998). Dengan demikian, pembelajaran pada waktu tertentu dapat berbeda antara kelompok yang tuntas dengan yang tidak, dalam jam yang sama, guru serta kelas yang sama pula. Dalam hal ini guru berperan dalam penentuan dan pelaksanaan model atau strategi yang sesuai untuk dilakukan pada kedua kelompok belajar tersebut agar dapat meningkatkan hasil belajar siswa.

Berdasarkan hasil pengalaman di lapangan, sistem perbaikan atau remedial sering dilakukan diluar jam pelajaran, seperti saat pulang sekolah. Hal ini tentu menimbulkan beberapa dampak diantaranya menyita waktu yang cukup lama jika jumlah siswa yang remedial cukup banyak, kondisi siswa yang sudah lelah sehingga menurunkan daya konsentrasi, serta adanya penambahan jam mengajar guru yang berdampak pada penambahan biaya bagi sekolah tertentu. Dengan penerapan model kelas multidimensional, diharapkan dapat mengatasi permasalahan tersebut sehingga kegiatan pembelajaran menjadi lebih optimal.

Penerapan model kelas multidimensional ini masih sangat jarang diterapkan khususnya di Indonesia. Penelitian ini diharapkan dapat mendorong seluruh siswa mencapai ketuntasan minimal atau diatasnya dengan melihat aspek-aspek pengelolaan kelas dan strategi pembelajaran dengan menerapkan model kelas multidimensional. Penelitian ini bertujuan untuk mengetahui implementasi model kelas multidimensional 
sebagai inovasi pembelajaran abad 21 dalam meningkatkan hasil belajar IPA kelas 7 .

\section{METODE}

Pendekatan yang digunakan dalam penelitian ini adalah Penelitian Tindakan Kelas (PTK), artinya penelitian ini berbasis pada masalah di kelas. Penelitian ini menggunakan rancangan model Kemmis \& Mc. Taggart (Arikunto, 2006) dengan tahapan pelaksanaan yang meliputi perencanaan (plan), tindakan (act), pengamatan (observe), serta refleksi (reflection) yang bertujuan untuk meningkatkan hasil belajar. Subjek penelitian siswa kelas 7G tahun pelajaran 2018/2019 berjumlah 28 siswa. Penelitian dilaksanakan bulan Januari Maret 2019 di Madrasah Tsanawiyah Pembangunan UIN Jakarta. Dalam pelaksanaannya, penelitian ini terdiri atas tiga siklus dan dua kali pertemuan untuk tes hasil belajar.

Data nilai hasil belajar didapatkan dengan menggunakan persamaan :

Nilai Siswa $=\frac{\text { Skor Total }}{\text { Skor Maksimal }} \times 100$

Tabel 1. Kriteria Belajar Minimal (KBM) IPA MTs Pembangunan UIN Jakarta

\begin{tabular}{ll}
\hline Nilai & Kategori \\
\hline$\geq 75$ & Tuntas \\
\hline$<75$ & Tidak Tuntas \\
\hline
\end{tabular}

Adapun persentase ketuntasan kelas dapat dicari dengan menggunakan rumus dibawah ini:

Klasikal $=\frac{\text { Jumlah Siswa } \text { Tuntas }}{\text { Jumlah } \text { Total Siswa }} \times 100 \%$

Tabel 2. Kriteria Ketuntasan Hasil Belajar

\begin{tabular}{ll}
\hline $\begin{array}{l}\text { Persentase } \\
\text { Ketuntasan Belajar }\end{array}$ & Kategori \\
\hline$\geq 80 \%$ & Tuntas \\
\hline$<80 \%$ & Tidak Tuntas \\
\hline
\end{tabular}

Indikator keberhasilan dalam penelitian ini ditentukan dari tercapainya ketuntasan hasil belajar siswa pada penilaian sebelumnya. Penelitian ini akan selesai jika nilai siswa materi sebelumnya telah tuntas seluruhnya.

\section{HASIL DAN PEMBAHASAN}

Penelitian ini terdiri atas 3 siklus. Sebelum memulai siklus 1, dilakukan pendataan siswa yang pada materi sebelumnya (Sistem Organisasi Kehidupan) tidak tuntas. Didapatkan sebanyak 6 siswa yang memiliki nilai dibawah KBM.

\section{Siklus 1}

Siswa dibagi kedalam dua kelompok, yaitu kelompok pertama yang sudah tuntas materi Sistem Organisasi Kehidupan dan kelompok lainnya yang belum tuntas materi tersebut. Penelitian siklus 1 dilaksanakan menggunakan model problem based learning pada materi Interaksi Makhluk Hidup dengan Lingkungan selama 2 jam pelajaran $(2 \times 40$ menit). Kedua kelompok mendapatkan materi yang sama tentang Interaksi Makhluk Hidup dengan Lingkungannya pada satu jam pertama. Pada satu jam berikutnya, kelompok yang sudah tuntas diberikan tugas, sedangkan kelompok yang belum tuntas dikelompokkan untuk dilakukan remedial teaching menggunakan metode tanya jawab model make a match. Setelahnya dilakukan evaluasi tertulis dan didapatkan 6 siswa tersebut memiliki nilai dibawah KBM.

\section{Siklus 2}

Pada siklus ini, guru kembali mengajarkan materi tentang Interaksi Makhluk hidup dengan lingkungan kepada kelompok yang sudah tuntas maupun belum. Model yang digunakan picture and picture. Satu jam berikutnya, kelompok yang telah tuntas diberikan tugas, sedangkan kelompok yang belum tuntas kembali dilakukan remedial teaching menggunakan metode tanya jawab menggunakan media gambar. Setelahnya dilakukan evaluasi tertulis dan didapatkan dari 6 siswa yang belum tuntas, 2 siswa mendapat nilai dibawah KKM.

\section{Siklus 3}

Pada siklus ini, guru melanjutkan materi untuk kedua kelompok menggunakan model discovery learning. Satu jam berikutnya, kelompok yang sudah tuntas diberikan tugas, sedangkan yang belum tuntas kembali diberikan remedial teaching menggunakan model inquiry menggunakan lembar latihan berisi soal yang harus dikerjakan siswa. 
Setelah dilakukan evaluasi tertulis, 4 siswa tersebut mendapat nilai diatas KKM. Adapun persentase ketuntasan siswa pada setiap siklus terdapat pada tabel 3.

Tabel 3. Peningkatan Hasil Belajar IPA Menggunakan Model Mutidimensional

\begin{tabular}{lll}
\hline Siklus & $\begin{array}{l}\text { Persentase } \\
\text { Ketuntasan }\end{array}$ & $\begin{array}{l}\text { Kategori } \\
\text { Ketuntasan }\end{array}$ \\
\hline Awal & $78,5 \%$ & Tuntas \\
\cline { 2 - 3 } & $21,5 \%$ & Tidak Tuntas \\
\hline Siklus 1 & $78,5 \%$ & Tuntas \\
\cline { 2 - 3 } & $21,5 \%$ & Tidak Tuntas \\
\hline Siklus 2 & $85,7 \%$ & Tuntas \\
\cline { 2 - 3 } & $14,3 \%$ & Tidak Tuntas \\
\hline Siklus 3 & $100 \%$ & Tuntas \\
\hline
\end{tabular}

Berdasarkan data pada tabel 3, dapat dijelaskan bahwa hasil belajar siswa yang tidak tuntas pada materi sebelumnya dapat menuntaskan nilai dan menyamai kedudukan dengan siswa tuntas lainnya. Data tersebut menunjukkan bahwa penerapan model kelas multidimensional dapat meningkatkan hasil belajar IPA. Persentase perbandingan hasil belajar siswa pada setiap siklus ditunjukkan pada Gambar 1.

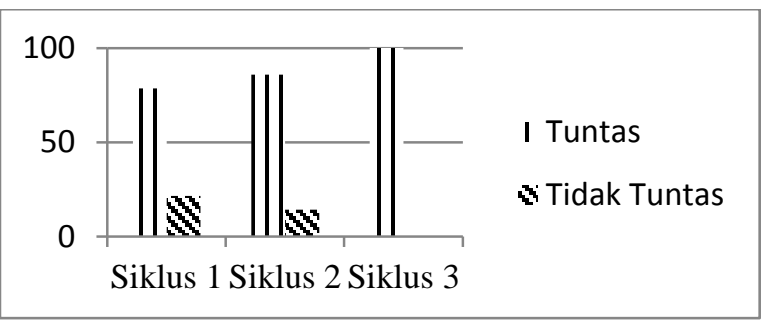

Gambar 1. Diagram Peningkatan Hasil Belajar IPA Siswa

Berdasarkan hasil penyajian data pada siklus 1, 2, dan 3, model pembelajaran multidimensional dapat meningkatkan hasil belajar IPA siswa kelas 7G MTs Pembangunan UIN Jakarta. Pada siklus 1 didapatkan jumlah siswa yang perbaikan tidak mengalami peningkatan setelah diberikan remedial couching, yaitu sebanyak 6 siswa dari 28 siswa dengan persentase ketuntasan sebesar 78,5\%. Hal ini disebabkan karena siswa sebelumnya tidak ada informasi bahwa pada hari tersebut akan diadakan perbaikan sehingga siswa merasa belum siap. Pada siklus 1, kelompok siswa yang tidak tuntas dilakukan remedial teaching menggunakan model make a match dengan media kartu. Hal ini cukup membuat siswa tertarik untuk belajar sekaligus berusaha mencocokkan antara gambar dengan pernyataan yang berhubungan dengan nama bagian atau fungsi yang sesuai.

Pada siklus 2 didapatkan jumlah siswa yang tuntas sebanyak 2 siswa dengan persentase ketuntasan sebesar $85,7 \%$. Pada siklus ini metode yang digunakan adalah tanya jawab menggunakan media gambar. Siswa merasa lebih siap menghadapi evaluasi kali ini karena sudah ada informasi sebelumnya tentang perbaikan. Remedial teaching menggunakan metode tanya jawab menggunakan gambar juga cukup efektif diterapkan pada pembelajaran. Hal ini dikarenakan melalui tanya jawab terjadi pertukaran informasi, pemecahan masalah dan pengambilan keputusan secara bersama-sama. Dengan jawaban-jawaban yang disampaikan siswa, guru dapat mengetahui tingkat penguasaan dan pemahaman materi siswa secara langsung (Subana dan Sunarti, 2009:198).

Pada siklus 3 didapatkan jumlah siswa yang tuntas sebanyak 4 siswa dengan persentase ketuntasan $100 \%$. Hal ini menunjukkan bahwa pada siklus ini semua siswa memiliki nilai diatas KBM. Model yang digunakan adalah inquiry menggunakan lembar soal sebagai instrumennya. Model ini dinilai sesuai untuk diterapkan karena dapat meningkatkan kemampuan ingatan dan pemahaman terhadap materi pembelajaran. Model ini melibatkan peran siswa secara aktif sehingga mendorong siswa untuk memperkaya cara berpikir dalam memecahkan masalah (Paizaluddian, 2013:220).

Ketercapaian hasil belajar siswa kelompok tidak tuntas pada materi selanjutnya adalah sebesar 100\%. Dari 6 siswa yang mengikuti materi baru sekaligus perbaikan, ketika evaluasi materi selanjutnya, yaitu Interaksi Makhluk Hidup dengan Lingkungannya, siswa tersebut memiliki nilai diatas KKM. Hal ini menunjukkan siswa yang perbaikan mampu menyamakan kedudukan dengan siswa yang tuntas. Meskipun dilaksanakan pada jam pelajaran, dimana waktu cukup terbatas, siswa tetap memiliki kesempatan yang sama untuk perbaikan dan siswa yang sudah tuntas memiliki kesempatan untuk melanjutkan materi selanjutnya. 
Model kelas multidimesional merupakan model yang menekankan pada penggunaan berbagai pendekatan yang dapat mendukung proses pembelajaran yang efektif. Model ini juga memberikan kesempatan bagi siswa yang belum tuntas pada materi sebelumnya untuk dapat mengikuti materi pembelajaran berikutnya dan melakukan perbaikan pada jam pelajaran. Hal ini sangat bermanfaat untuk memaksimalkan proses pembelajaran di kelas. Didalam jam pelajaran siswa yang sudah tuntas tetap dapat melanjutkan materi selanjutnya dan siswa yang belum tuntas mendapatkan haknya untuk dapat perbaikan tanpa harus mengorbankan waktu diluar jam pelajaran untuk perbaikan. Dimana kondisi diluar jam pelajaran tentu berbeda dengan kondisi siswa saat jam pelajaran. Siswa yang melakukan remedial diluar jam pelajaran memiliki kondisi dan stamina yang berbeda sehingga hal ini dinilai tidak efektif untuk dilakukan. Selain itu, penerapan model kelas multidimensional dapat mengurangi beban mengajar guru diluar jam pelajaran. Pekerjaan guru menjadi lebih ringan, sehingga kegiatan diluar jam pelajaran dapat dimanfaatkan oleh guru untuk persiapan pembelajaran selanjutnya.

Penerapan model kelas multidimensional juga memberikan kelebihan dari segi pengeluaran anggaran yang dilakukan sekolah apabila guru melakukan perbaikan diluar jam sekolah. Anggaran ini dapat dialokasikan untuk kebutuhan lain yang dapat menunjang proses belajar mengajar yang lebih efektif yang menunjang pembelajaran abad 21.

Guru tidak boleh memberikan pelayanan yang berbeda di antara siswa-siswanya, baik mereka yang berkemampuan tinggi maupun yang rendah karena mereka memiliki posisi dan hak yang sama, namun guru memberi perlakuan yang sesuai kemampuannya. Guru menyampaikan satu paket pesan yang sama dan melakukan pemulihan dan penguatan bagi yang tertinggal dan atau pengayaan bagi mereka yang telah memiliki kompetensi ideal.

\section{PENUTUP}

Berdasarkan hasil penelitian dan pembahasan yang telah diuraikan sebelumnya, dapat disimpulkan bahwa penerapan model kelas multidimensional dapat meningkatkan hasil belajar siswa pada pelajaran IPA kelas 7. Hal ini dibuktikan dengan peningkatan persentase siswa yang tuntas pada setiap siklus.

Beberapa saran berdasarkan penelitian tersebut adalah sebagai berikut. Pertama bagi peneliti selanjutnya diharapkan dapat memperluas subjek penelitian. Kedua untuk memfasilitasi siswa belajar hendaknya dapat memperbanyak sumbersumber bacaan, media pembelajaran, komputer dan internet yang menunjang kegiatan belajar mengajar. Ketiga guru hendaknya memilih berbagai model pembelajaran yang sesuai dengan kondisi kedua kelompok belajar agar model kelas multidimensional ini dapat berjalan dengan efektif.

\section{Ucapan Terima Kasih}

Penelitian ini dilakukan tidak terlepas dari arahan, bimbingan, dan dukungan dari berbagai pihak. Maka dari itu penulis ingin mengucapkan terima kasih kepada :1) Bapak Prof Dr. Dede Rosyada dan tim dari Fakultas Ilmu Tarbiyah dan Keguruan UIN Jakarta atas ide, gagasan dan bimbingannya dalam pengembangan model kelas multidimensional ini; 2) Direktur Madrasah Pembangunan UIN Jakarta, Bapak Dr. H. Baharissalim, MA yang telah mendukung terlaksananya penelitian ini.

Seluruh civitas akademika di lingkungan Madrasah Pembangunan, khususnya di unit MTs Pembangunan UIN Jakarta atas kesempatan yang telah diberikan kepada penulis untuk terus belajar dan berkarya.

\section{DAFTAR PUSTAKA}

Arikunto, Suharsimi (2010). Prosedur Penelitian Suatu Pendekatan Praktik. Jakarta: PT Rineka Cipta.

Abdelhamid, T.M (2008). 'The Multidimensional Learning Model: A Novel Cognitive Psychology Based Model for Computer Assisted Instruction in Order to Improve Learning in Medical Students', Medical Education Online, 4(1), pp. 1-8. 
Greenstein, L (2012) Assessing $21^{\text {st }}$ Century Skills: A Guide to Evaluating Mastery and Authentic Learning, London: Sage Publications Ltd.

Kauchak, Donald P. and Paul D Eggen (1998) Learning and Teaching, Research Based Methods. Boston: Allyn and Bacon.

Paizaluddian dan Ermalinda (2013) Penelitian Tindakan Kelas (Classroom Acton Research) Panduan Teoritis dan Praktis. Bandung: Alfabeta.
P21 (2008) 21st Century Skills, Education and Competitiveness. Washington DC: Partnership for 21st Century Skills.

Subana dan Sunarti (2009) Strategi Belajar Mengajar Bahasa Indonesia, Berbagai Pendekatan, Metode, Teknik dan Media Pengajaran. Bandung: Pustaka Setia.

Sugiarti, dkk. (2018) 'Pembelajaran Abad 21 di SD', Prosiding Seminar dan Diskusi Nasional Pendidikan Dasar. pp. 439-444.. 